\title{
Teaching Effectiveness During Lectures in Universiti Sains Malaysia School of Medical \\ Sciences
}

Submitted: 02-05-2018

Accepted: 11-07-2018

Online: 28-09-2018

\author{
Muhd Al-Aarifin Ismail, Nik Mohd Rizal Mohd Fakri, \\ Jamilah Al-Muhammadi Mohammad, Mohd Zarawi Mat Nor, \\ Anisa Ahmad, Muhamad Saiful Bahri Yusoff \\ Department of Medical Education, School of Medical Sciences, \\ Universiti Sains Malaysia, Kelantan, MALAYSIA
}

To cite this article: Ismail MA-A, Mohd Fakri NMR, Mohammad JA-M, Mat Nor MZ, Ahmad A, Yusoff MSB. Teaching effectiveness during lectures in Universiti Sains Malaysia School of Medical Sciences. Education in Medicine Journal. 2018;10(3):13-22. https://doi.org/10.21315/eimj2018.10.3.2

To link to this article: https://doi.org/1.21315/eimj2018.10.3.2

\begin{abstract}
Lecturers are expected to teach effectively and evaluating their teaching effectiveness are essential to ensure students get the best learning experience. A systematic evaluation of teaching behaviours with a proper feedback mechanism will help to improve their teaching effectiveness. Improvement of teaching effectiveness will result in better students' learning experience, and thus attaining the intended educational outcomes. This study aimed to evaluate teaching effectiveness among lecturers by assessing their teaching behaviours during lectures. A cross-sectional study was conducted on lecturers in a Malaysian public medical school. Their teaching behaviours were rated by 30 trained pre-clinical medical students using Teacher Behaviour Inventory (TBI) on seven aspects - organisation, speechpacing, clarity, enthusiasm, interaction, rapport, and disclosure. A total of 55 lecturers were rated by the medical students. The organisation and speech-pacing aspects were highly rated as the mean scores were 4.02 and 4.15, respectively. The clarity, enthusiasm, interaction, and rapport aspects attained satisfactory level as the mean scores ranged from 3.10 to 3.59. The disclosure aspect was poorly rated as the mean score was 2.20. Eventhough all lecturers in this school are considered expert in their area, findings from this study suggest that some teaching behaviour need some improvement. Findings from this study also provide useful data for the medical school to chart direction of faculty development activities to improve their lecturers' teaching effectiveness during lectures.
\end{abstract}

Keywords: Teaching evaluation, Teaching effectiveness, Students rating, Teacher behaviours, Teaching assessment Universiti Sains Malaysia, 16150 Kubang Kerian, Kelantan, Malaysia | Email: alaarifin@, usm.my

\section{INTRODUCTION}

Teaching effectiveness is defined as the aggregated effects of a complex set of in-classroom teacher behaviours on students learning (1). The question of what constitutes effective teaching has been researched for decades (2). There is much diversity in the literatures discussing about dimensions of effective teaching (3). For example, Hativa, Barak and Simhi (4) propose four dimensions of teaching effectiveness which are clarity, interest, organisation, and positive classroom 
climate. Young and Shaw (5) propose six major dimensions of effective teaching value of the subject, motivating students, a comfortable learning atmosphere, organisation of the subject, effective communication, and concern for students' learning. Meanwhile Murray (6) focuses mainly on teaching behaviours which include clarity, enthusiasm, interaction, organisation, disclosure, rapport, speech quality, and pace. Eventhough different authors suggest different attributes of effective teaching, they are basically discussing about almost similar attributes. Knowing attributes of effective teaching is crucial as they were used as a benchmarks for teachers to improve their teaching performance.

A lot of studies conducted to investigate the impacts of effective teaching on student performance. Generally, effective teaching will results on better student examination performance $(7,8)$. Therefore, evaluating teaching effectiveness is important to ensure a high quality education provided to students (9) and produce good educational outcomes. According to Murray, measurement of teaching effectiveness in higher education studies includes: (a) evaluating students' learning, for example, by measuring student performance on a common final examination; (b) assessing students' motivation to further learning; and (c) feedback from stakeholders such as student ratings (6). Other than students rating (the most commonly used), literatures also suggest several other sources of evidence for teaching evaluation such as selfevaluation, peer evaluation, and portfolios (10). Generally, teaching evaluation can be categorised into formative and summative, depending on the purposes of evaluation (11). The main aim of formative evaluation is to improve and shape the quality of teaching, while summative evaluation is to judge overall teaching performance for decision-making about something such as promotion and tenure (10).

It is worth noting that, some might have misunderstanding about difference between teaching expertise and content expertise. Previously they were assumed as similar attributes - where content experts were considered as equal to good teachers (12). However, this assumption was not supported by evidence because it has been shown that both attributes are different entity, but interconnected with each other (13). A teacher who might have excellent content knowledge might be a very ineffective teacher. Conversely, a teacher who might have relatively lesser content knowledge, she/he could be very effective in teaching (14). Thus, to be an effective teacher, one should not only rely on knowledge acquisition per se, it should also be incorporated with teaching skills. Luckily, the teaching skills are transferable skills that can be taught and learned through deliberate training and practice. However, across the globe, getting faculty members to join in the faculty development activities for harnessing their teaching skills are not easy due to multiple factors particularly related to time-constraints and rewards (15). Perhaps with proper feedback system, i.e. teaching evaluation system, at least we can allow them to improve effectiveness of their teaching through reflective learning (16).

The aim of the present study is to answer three questions which are: (a) what are the positive aspects of teaching behaviours among lecturers during lectures?; (b) what are the aspects of teaching behaviours that need improvement?; and (c) what are the aspects of teaching behaviours that need to be concerned? Findings from this study can be used as a basis to guide the school administrators to properly plan their faculty development programme in the future.

\section{MATERIALS AND METHODS}

\section{Study Setting and Population}

A cross sectional study was carried out on the faculty members who delivered lectures for the pre-clinical year medical students in School of Medical Sciences, Universiti 
Sains Malaysia. Simple random sampling was applied to select faculty members based on the name list provided by the academic office. Sample size was estimated by SPCC (sample size calculaton software).

\section{Study Instrument}

This study used the 32-item Teacher Behaviour Inventory (TBI-32) to measure seven aspects of teaching behaviours - clarity, enthusiasm, interaction, organisation, disclosure, speech-pacing, and rapport (17). Its Cronbach's alpha was more than 0.9 , indicating a high level of internal consistency (18). The use of TBI-32 requires evaluators to observe the lecturers' teaching behaviours while delivering lectures. The evaluator rate each item of TBI-32 using 5-point scale, ranging from 1 (almost never) to 5 (almost always). Out of 32 items, there are two negative items that require reversed scoring for the analysis purpose (Items 27 and 28). The mean scores of TBI-32 are categorised into positive areas (any scores equal to or more than 4.00), areas for improvement (any scores in between 3.00 and 3.99), and areas of concern (any scores less than 3.00).

Two interpretation approaches of TBI scores that are high-inference and lowinference teaching behaviours (3). Highinference behaviours refer to global and abstract traits such as clarity, enthusiasm, rapport, etc. On the other hand, lowinference behaviours refer to specific and concrete teaching behaviours that can be recorded with very little inference or judgement on the part of a classroom observer such as "points out practical applications of concepts" and "explains subject matter in familiar colloquial language" (Table 2) (6). In comparison to high-inference, low-inference teaching behaviours were proven to be more valid and had positive impacts on students' learning, students' performance, and overall teaching effectiveness (6). From that notion, both interpretation approaches were reported and discussed in this paper.

\section{Ethical Approval}

The study protocol was approved by the Universiti Sains Malaysia Human Ethics Committee (JEPeM Code: USM/ JEPeM/15070246). Writen informed consent was signed by participants prior to the study begun. Privacy and confidentiality were assured.

\section{Data Collection}

Thirty students volunteered as evaluators. They were trained to evaluate teaching behaviours in a specific training session. Objectives of the training session were to brief them about the research, explain the roles of a student evaluators, familiarisation and calibration on the use of TBI-32. The training session was conducted in three hours. To unsure the student rating are reliable, inter-rater reliability (IRR) for pre $\&$ post training session were analysed. IRR refers to the relative consistency in ratings provided by multiple evaluators of multiple questions. It is required to demonstrate consistency among observational ratings provided by multiple coders $(4,5)$. It quantifies the degree of agreement between all student evaluators who had independently rate the lecturers before and after the training session. The IRR was assessed using a two-way mixed, consistency, average-measures Intraclass Correlation Coefficient (ICC). The analysed data showed the ICC were in the excellent range for pre-training (0.974) and posttraining (0.988), indicating that evaluators have a high degree of agreement among the evaluators. This finding has supported that the evaluation of low-inference behaviour is reliable.

During data collection, the trained students were asked to evaluate teaching behaviour of their instructors after several teaching sessions. The instructors were not informed earlier which of their lecture session will be evaluated, when will the rating session be done, and who will rate them to ensure the authenticity of their teaching behaviours. 


\section{RESULT}

A total of 55 subjects participated in this study. There are $18(32.7 \%)$ males and $37(67.3 \%)$ females; 42 (76.4\%) Malay and 13 (25.6\%) non-Malay; 19 (34.5\%) of them were clinical based, whereas $36(65.5 \%)$ were non-clinical based. In terms of designation, $35(63.6 \%)$ of them were lecturers while the remaining were professors and associate professors (Table 1).

Table 2 summarises the overall performance of teaching behaviours by the seven aspects of TBI-32. The organisation and speechpacing aspects were rated as positive areas, indicating the the lecturers' strength. Four aspects of teaching behaviours that were clarity, enthusiasm, interaction, and rapport were rated as areas for improvement. Unfortunately, the disclosure aspect was rated as an area of concern, indicating the lecturers' weak point.

In term of low-inference teaching behaviours, eight items were highly rated by the evaluators, 15 items were under area for improvement, and 10 items were under area of concern. The highest mean score for lowinference teaching behaviour was Item no. 28 , indicating that subjects have minimal problem with stutters, mumbles or slurs words. On the other hand, the lowest mean score for low-inference teaching behaviour was Item no. 24.

\section{DISCUSSION}

In this discussion part, the discussion of the seven aspects were arranged from positive areas to areas of concern based on their mean scores.

The organisation aspect is characterised by using heading \& subheading, putting outlines, giving clear signal for topic transition, giving preliminary overview, and stating objectives of each lecture. This study shows the lecturers are doing well in this aspect, and thus indicating they are skilful in delivering lectures in systematic and organised manner. The positive teaching behaviours might be due to the use of technology in lectures such as Power Point slides. This is aligned with the evidence showed lecturers who delivered lectures using Power Point slides were more positively rated in this aspect by students than lecturers who delivered using traditional blackboard or whiteboard (19). Nevertheless, two subareas of the organisation require improvement that include providing the overview of lectures and stating clear statements on the learning

Table 1: Demographic data (gender, race, clinical or non-clinical, nationality, and title of instructors)

\begin{tabular}{llcc}
\hline & Variable & Number of instructors, $\mathbf{n}(\%)$ & Total (\%) \\
\hline \multirow{2}{*}{ Gender } & Male & $18(32.7)$ & $55(100)$ \\
& Female & $37(67.3)$ & \\
& Malay & $42(76.4)$ & $55(100)$ \\
\multirow{5}{*}{ Expertise } & Chinese & $6(10.9)$ & \\
& Indian & $2(3.6)$ & \\
& Others & $5(9.1)$ & $55(100)$ \\
& Clinical & $19(34.5)$ & \\
\multirow{5}{*}{ Designationation } & Non-clinical & $36(65.5)$ & $55(100)$ \\
& Malaysian & $49(89.1)$ & \\
& Non-Malaysian & $6(10.9)$ & \\
& Professor & $8(14.6)$ & \\
& Assoc. Professor & $12(21.8)$ & \\
& Lecturer & $35(63.6)$ &
\end{tabular}


Table 2: Mean score for the high-inference and low-inference teaching behaviours

\begin{tabular}{|c|c|c|c|c|}
\hline Domain* & Item no. & Low-inference teaching behaviour & Mean & SD \\
\hline \multirow[t]{7}{*}{ Clarity } & & & 3.59 & 0.45 \\
\hline & 1 & $\begin{array}{l}\text { Stresses most important points by pausing, speaking slowly, raising voice, } \\
\text { and so on }\end{array}$ & 3.90 & 0.51 \\
\hline & 2 & Points out practical applications of concepts & 3.88 & 0.51 \\
\hline & 3 & Answers students' questions thoroughly & 2.91 & 0.66 \\
\hline & 4 & Explains subject matter in familiar colloquial language & 4.18 & 0.32 \\
\hline & 5 & Suggests ways of memorising complicated ideas & 2.88 & 0.69 \\
\hline & 6 & Periodically summarises points previously made & 3.77 & 0.50 \\
\hline \multirow[t]{5}{*}{ Enthusiasm } & & & 3.32 & 0.65 \\
\hline & 7 & Moves about while lecturing & 3.06 & 0.79 \\
\hline & 8 & Gestures with hands or arms & 3.60 & 0.64 \\
\hline & 9 & Gestures with head or body & 3.26 & 0.63 \\
\hline & 10 & Exhibits facial gestures or expressions & 3.35 & 0.61 \\
\hline \multirow[t]{6}{*}{ Interaction } & & & 3.10 & 0.63 \\
\hline & 11 & Encourages students to ask questions or make comments during lectures & 2.97 & 0.69 \\
\hline & 12 & Praises students for good ideas & 2.45 & 0.73 \\
\hline & 13 & Asks questions of class as a whole & 3.52 & 0.76 \\
\hline & 14 & Presents challenging, thought-provoking ideas & 3.25 & 0.69 \\
\hline & 15 & Asks if students understand before proceeding to next topic & 3.33 & 0.65 \\
\hline \multirow[t]{6}{*}{ Organisation } & & & 4.02 & 0.41 \\
\hline & 16 & Uses headings and subheadings to organise lectures & 4.16 & 0.37 \\
\hline & 17 & Puts outline of lecture on blackboard or overhead screen & 4.03 & 0.44 \\
\hline & 18 & Clearly indicates transition from one topic to the next & 4.03 & 0.48 \\
\hline & 19 & Gives preliminary overview of lecture at the beginning of class & 3.94 & 0.46 \\
\hline & 20 & States objectives of each lecture & 3.93 & 0.45 \\
\hline \multirow[t]{5}{*}{ Disclosure } & & & 2.20 & 0.75 \\
\hline & 21 & Advises students as to how to prepare for tests or exams & 2.58 & 0.84 \\
\hline & 22 & Provides sample exam questions & 2.13 & 0.90 \\
\hline & 23 & $\begin{array}{l}\text { Tells students exactly what is expected of them on tests, essays or } \\
\text { assignments }\end{array}$ & 2.43 & 1.06 \\
\hline & 24 & Reminds students of test dates or assignment deadlines & 1.67 & 0.56 \\
\hline \multirow[t]{5}{*}{ Speech-pacins } & & & 4.15 & 0.38 \\
\hline & 25 & Speaks clearly & 4.23 & 0.32 \\
\hline & 26 & Speaks at appropriate pace & 4.19 & 0.40 \\
\hline & 27 & Voice lacks proper modulation (speaks in monotone) ${ }^{* *}$ & 3.88 & 0.63 \\
\hline & 28 & Stutters, mumbles or slurs words ** & 4.30 & 0.33 \\
\hline \multirow[t]{5}{*}{ Rapport } & & & 3.24 & 0.53 \\
\hline & 29 & Announces availability for consultation outside of class & 2.96 & 0.64 \\
\hline & 30 & Offers to help students with problems & 3.29 & 0.56 \\
\hline & 31 & Shows tolerance of other points of view & 3.13 & 0.53 \\
\hline & 32 & Talks with students before or after class & 3.56 & 0.57 \\
\hline
\end{tabular}

Notes: "domain refers to high-inference teaching behaviour; "*negative items with reverse scored Positive areas: any scores equal to or more than 4.00 Areas for improvement: any scores in between 3.00 and 3.99 Areas of concern: Any scores less than 3.00 
outcomes of lectures. Providing a big picture of a lesson prior to the delivery of content is vital to establish context and relevance of the subject matters, and thus stimulate prior knowledge of students for learning (20). Whereas, stating clear learning outcomes of a lesson prior to the delivery of content will gain students' attention, and thus engage them in the learning activities (21). Apart from that, this study provides useful feedback on specific teaching behaviours related to the organisation aspect for the lecturers to improve in the future.

Speech and pacing aspect is mainly characterised by the clarity and pace of voice while delivering a lesson. This study shows the lecturers did well in this aspect and indeed got higher mean score than a previous study conducted on lecturers in University of Western Ontario using similar instrument (6). Despite positive evaluation, one area for improvement related to speechpacing aspect is the lectures should work on their monotonous voice in delivering lectures. It is worth mentioning that monotonous lectures can have unwanted consequence on students' comprehension and academic performance (22). And it is a real communication killer. It happens when the variety of our voice's pitch does not vary. It is impossible for students to maintain any interest in what we are saying. Therefore, any effort to improve this area of improvement might provide positive impact on students' learning experience during medical training. Probably, many lecturers do not even realise that their lectures are monotonous. Thus, we encourage lecturers to get regular feedback from their students and improve themselves from time to time.

Clarity aspect is characterised by the ability of lecturers to emphasise on important concept, provide practical application of the concept, explain and summarise the concept in familiar language and uncomplicated manner through appropriate verbal and non-verbal messages (23). Unfortunately, this study found most of the clarity aspect were areas for improvement and of concern, except for explaining in familiar language. Similar findings were reported by a previous study conducted in several academic disciplines (i.e., art and humanities, natural sciences, and mathematics) at University of Western Ontario using similar tool (24). Recent meta-analysis revealed teacher clarity has a moderate effect on student affective and cognitive learning (25), thus provides evidence to signify the substantial relationships exist between teaching clarity and student learning. Several other studies reported the same findings whereby using familiar language to explain concepts (26), providing a good lecture summary (27), providing concrete and constructive answers to questions, and explaining concepts in uncomplicated manner (28) will facilitate student learning process. This study pointed out that the clarity aspect of teaching behaviours among the lecturers need to be addressed by the medical school through a proper faculty development programme. Improving this aspect will improve the quality of students' learning experience during medical training.

Enthusiasm aspect is related to lectures' movements and gestures during a teaching session to promote learning. In this study, the lecturers' enthusiasm were rated as areas for improvement and had lower mean score than a previous study that measured similar aspect (24). However, this relatively different mean scores should be interpreted cautiously due to different terms used to describe the teaching behaviours - enthusiasm used in this study and mannerism used in the previous study (6). It is noteworthy to highlight, previous studies showed that teachers with enthusiastic behaviours such as appropriate use of gestures and movements in the classroom (29) were considered as effective teaching behaviours (30) and positively perceived by students (31). Consequently, this study indicated the medical school should plan activities to train its lecturers to embrace this teaching behaviour to improve their teaching effectiveness and students' learning experience. 
Interaction aspect is dealing with lecturers' ability to encourage students to participate in learning activities through appropriate use of questioning techniques, effective feedback, assigning appropriate learning tasks, and assessing learners' understanding on the topic. Literatures have shown interactive behaviours are associated with student development (32) and result in greater academic performance as well as positive personal development (33). This study showed the lecturers' interactive behaviours were considered as areas for improvement and similar finding was reported in a previous study done in University of Western Ontario (9). This study clearly points out important and significant areas of teaching behaviours that need to be improved, and thus a microteaching session should be planned to train the lecturers on an efficient technique for learning effective teaching behaviours (34). Improving faculty-student interaction during teaching session will be beneficial to students' learning experience.

Rapport is described as a good understanding of someone and an ability to communicate well with them (35), for examples lecturers offer consultation to students outside class, provide help to students with problems, show tolerance with other opinion and talk to students prior to class begins. Teaching effectiveness is significantly associated with lecturers' rapport (36), and thus developing good rapport is important due to its favourable outcomes such as good attitudes toward teachers and courses, increased student motivation, perceived learning positively (37) and promote active participation in classroom (38). This study found the lecturers' rapport aspect was an area for improvement, and thus need to be improved. Nevertheless, this result should be interpreted with cautions, for examples the low score on "offering help to students with problem" and the poor score on "announces availability for consultation outside of class" might be due to the lecturers did not clearly mention it during lecture sessions, but in reality they are willing to help and provide consultation to their students at any time.

Another reason for the low and poor scores might be due to the large class size and limited time provided that lead to they overlook on this matter. Apart from that, literatures have recommended several ways in developing rapport with students such as calling students by name, emphasising active learning, knowing their interests and hobbies, and making eye contact with students (39). Since these teaching behaviours can be learnt, therefore microteaching programme can be offered to help lecturers to improve their teaching behaviours (34).

In TBI, disclosure is about teachers giving guidance to students on examination process, providing samples of examination questions, telling about examination expectation, and reminding about test dates and assignment deadlines. It was not a surprise to have poor scores on this aspect due to disclosing examination information is not a norm or practice in the medical school, and most of the lecturers consider disclosure of examination information to students might compromise the quality of examination. Conversely, a previous study that was conducted in the west reported better scores in this aspect (6), suggesting different rating by learners on lecturers' disclosure behaviour might be due to different educational practices that shape certain teaching behaviours. Therefore, interpretation of this aspect should be made with caution and within the context. Even so, many research have mentioned that the main source of stress among medical students is due to the academic requirement particularly the examination (40-42), and therefore improving disclosure behaviours might lead to reduction of student stress and thus improve their psychological well-being (43). 


\section{CONCLUSION}

This study provided useful data for the medical school to chart direction of faculty development activities to improve their lecturers' teaching effectiveness during lectures. As we know, teachers should be able to demonstrate a good teaching behaviours. Studies have found that, teaching expertise is not the same with medical expertise. Apart from being expert in their area, lecturers must also learn about pedagogy. It is also important that they are familiar with learning theories which underpin teaching effectiveness. To improve teaching skills particularly in lecture, teachers must always learn about the best practice in delivering instruction. They must learn from others, discuss and share experience with their colleagues to look at the range of approaches and techniques that they can apply in the classroom. We do encourage all institutions to continuously evaluate their lecturers teaching behaviour and provide feedback to them. This is crucial for continuous improvement.

\section{ACKNOWLEDGEMENTS}

This study was funded by the Universiti Sains Malaysia (USM) Short Term Grant (304/PPSP/61313161). We would like to thank USM for allowing us to conduct this study in their instituition and our greatest appreciation to all 30 students who had participated in this study as student evaluators.

\section{REFERENCES}

1. Klassen RM, Tze VM. Teachers' selfefficacy, personality, and teaching effectiveness: a meta-analysis. Educational Research Review. 2014;12:59-76. https:// doi.org/10.1016/j.edurev.2014.06.001
2. Stronge JH, Ward TJ, Grant LW. What makes good teachers good? A cross-case analysis of the connection between teacher effectiveness and student achievement. J Teach Educ. 2011;62(4):339-55. https:// doi.org/10.1177/0022487111404241

3. Devlin $M$, Samarawickrema G. The criteria of effective teaching in a changing higher education context. Higher Education Research \& Development. 2010;29(2):11124.

4. Hativa N, Barak R, Simhi E. Exemplary university teachers: knowledge and beliefs regarding effective teaching dimensions and strategies. Journal of Higher Education. 2001;72(6):699-729. https://doi.org/10.1080 /00221546.2001.11777122

5. Young S, Shaw DG. Profiles of effective college and university teachers. Journal of Higher Education. 1999;70(6):670-86. https://doi.org/10.2307/2649170

6. Murray HG. Low-inference teaching behaviors and college teaching effectiveness: recent developments and controversies. The scholarship of tecaching and learning in higher education: an evidence-based perspective. The Netherlands: Springer; 2007. p. 145-200.

7. Griffith $\mathrm{CH}$, Georgesen JC, Wilson JF. Six-year documentation of the association between excellent clinical teaching and improved students' examination performances. Acad Med. 2000;75(10):S624. https://doi.org/10.1097/00001888-20001 0001-00020

8. Stehle S, Spinath B, Kadmon M. Measuring teaching effectiveness: correspondence between students' evaluations of teaching and different measures of student learning. Research in Higher Education. 2012;53(8):888-904. https://doi.org/10. 1007/s11162-012-9260-9 
9. Kozub RM. Student evaluations of faculty: concerns and possible solutions. Journal of College Teaching \& Learning (TLC). 2008;5(11):35-8.

10. Berk RA. Survey of 12 strategies to measure teaching effectiveness. International Journal of Teaching and Learning in Higher Education. 2005;17(1):48-62.

11. McKeachie WJ. Student ratings: the validity of use. Am Psychol. 1997;52(11): 1218-25. https://doi.org/10.1037/0003-066X. 52.11 .1218

12. Harden RM, Crosby J. AMEE Guide No 20: the good teacher is more than a lecturer - the twelve roles of the teacher. Med Teach. 2000;22(4):334-47. https://doi.org/ $10.1080 / 014215900409429$

13. Wilkerson L, Irby DM. Strategies for improving teaching practices: a comprehensive approach to faculty development. Acad Med. 1998;73(4):38796. https://doi.org/10.1097/00001888-1998 04000-00011

14. Ding C, Sherman H. Teaching effectiveness and student achievement: examining the relationship. Educational Research Quarterly. 2006;29(4):40-51.

15. Ahmed S. Tailoring online faculty development programmes: overcoming faculty resistance. Med Educ. 2013;47(5):535. https://doi.org/10.1111/ medu. 12192

16. Kolb AY, Kolb DA. Experiential learning theory as a guide for experiential educators in higher education. ELTHE: A Journal for Engaged Educators. 2017;1(1):7-44.

17. Hadie SNH, Hassan A, Talip SB, Yusoff MSB. The teacher behavior inventory: validation of teacher behavior in an interactive lecture environment. Teacher Development. 2018:1-14. https://doi.org/10 $.1080 / 13664530.2018 .1464504$
18. Streiner D, Norman G. Health measurement scales: a practical guide to their development and use. 4th ed. New York: Oxford University Press; 2008. https://doi.org/10.1093/acprof:oso/ 9780199231881.001 .0001

19. Frey BA, Birnbaum DJ. Learners' perceptions on the value of powerpoint in lectures. PA: University of Pittsburgh; 2002. p. 1-3.

20. Felder RM, Silverman LK. Learning and teaching styles in engineering education. Engineering Education. 1988;78(7):674-81.

21. Biggs J. Enhancing teaching through constructive alignment. Higher Education. 1996;32(3):347-64. https://doi.org/10.1007/ BF00138871

22. Holub E. Does intonation matter? The impact of monotony on listener comprehension. Italy: EUT Edizioni Universita di Trieste; 2010. p. 117-26.

23. Chesebro J, editor. Teacher clarity: a definition, review, and a profile of the clear teacher. Paper presented at the Meeting of the National Communication Association, Chicago, IL; 1999.

24. Murray HG, Renaud RD. Disciplinary differences in classroom teaching behaviors. New Directions for Teaching and Learning. 1995;1995(64):31-9. https://doi.org/10.1002/ tl.37219956406

25. Titsworth S, Mazer JP, Goodboy AK, Bolkan S, Myers SA. Two meta-analyses exploring the relationship between teacher clarity and student learning. Communication Education. 2015;64(4):385-418. https://doi. org/10.1080/03634523.2015.1041998

26. Goh C. Second language listening expertise. In: Johnson K, editor. Expertise in second language learning and teaching. London, UK: Palgrave Macmillan; 2005. p. 64-84. https://doi.org/10.1057/9780230523470_4 
27. Huang J. Challenges of academic listening in English: reports by Chinese students. College Student Journal. 2005;39(3):553.

28. Kiewra KA. How classroom teachers can help students learn and teach them how to learn. Theory into Practice. 2002;41(2):71-80. https://doi.org/10.1207/ s15430421 tip4102_3

29. Khanam A. Effect of immediacy on teacher's acceptance in university students. Journal of Arts and Social Sciences. 2014;1(1):70.

30. Chesebro JL, McCroskey JC. The relationship of teacher clarity and immediacy with student state receiver apprehension, affect, and cognitive learning. Communication Education. 2001;50(1):59-68. https://doi.org/10.1080/ 03634520109379232

31. Allen M, Witt PL, Wheeless LR. The role of teacher immediacy as a motivational factor in student learning: using meta-analysis to test a causal model. Communication Education. 2006;55(1):21-31. https://doi. org/10.1080/03634520500343368

32. Kim YK, Sax LJ. Student-faculty interaction in research universities: differences by student gender, race, social class, and firstgeneration status. Research in Higher Education. 2009;50(5):437-59. https://doi. org/10.1007/s11162-009-9127-x

33. Pascarella ET, Terenzini PT, Feldman KA. How college affects students. San Francisco, CA: Jossey-Bass; 2005.

34. Remesh A. Microteaching, an efficient technique for learning effective teaching. Journal of Research in Medical Sciences. 2013;18(2):158-63.

35. Cambridge Dictionaries Online. 2016 [cited 2016]. Available from: http://dictionary. cambridge.org/dictionary/english/rapport.
36. Van Giffen K. Influence of professor gender and perceived use of humor on course evaluations. Humor: International Journal of Humor Research. 1990;3(1):65-74. https:// doi.org/10.1515/humr.1990.3.1.65

37. Wilson JH, Ryan RG. Professor-student rapport scale six items predict student outcomes. Teaching of Psychology. 2013;40(2):130-3. https://doi.org/10.1177/ 0098628312475033

38. Frisby BN, Myers SA. The relationships among perceived instructor rapport, student participation, and student learning outcomes. Texas Speech Communication Journal. 2008;33(1):27-34.

39. Buskist W, Saville BK. Creating positive emotional contexts for enhancing teaching and learning. APS Observer. 2001;19:12-3.

40. Yen Yee L, Yusoff MSB. Prevalence and sources of stress among medical students in Universiti Sains Malaysia and Universiteit Maastricht. Education in Medicine Journal. 2013;5(4):34-41. https://doi.org/10.5959/ eimj.v5i4.190

41. Yusoff MSB. Impact of summative assessment on first year medical students' mental health. Int Med J. 2011;18(3):172-5.

42. Yusoff MSB, Rahim AFA, Yaacob MJ. Prevalence and sources of stress among Universiti Sains Malaysia medical students. Malays J Med Sci. 2010;17(1):30-7.

43. Dunn LB, Iglewicz A, Moutier C. A conceptual model of medical student wellbeing: promoting resilience and preventing burnout. Acad Psychiatry. 2008;32(1):4453. https://doi.org/10.1176/appi.ap.32.1.44 